\title{
Protocol
}

\section{Bone Marrow-Derived Macrophages (BMM): Isolation and Applications}

\author{
Joachim Weischenfeldt and Bo Porse ${ }^{1}$ \\ The Biotech Research and Innovation Centre, University of Copenhagen, 2200 Copenhagen, Denmark \\ Section for Gene Therapy Research, Department of Clinical Biochemistry, Copenhagen University Hospital, \\ 2100 Copenhagen, Denmark
}

\section{INTRODUCTION}

Bone marrow-derived macrophages (BMM) are primary macrophage cells, derived from bone marrow cells in vitro in the presence of growth factors. Macrophage colony-stimulating factor (M-CSF) is a lineage-specific growth factor that is responsible for the proliferation and differentiation of committed myeloid progenitors into cells of the macrophage/monocyte lineage. Mice lacking functional M-CSF are deficient in macrophages and osteoclasts and suffer from osteopetrosis. In this protocol, bone marrow cells are grown in culture dishes in the presence of M-CSF, which is secreted by L929 cells and is used in the form of L929-conditioned medium. Under these conditions, the bone marrow monocyte/macrophage progenitors will proliferate and differentiate into a homogenous population of mature BMMs. The efficiency of the differentiation is assessed using fluorescence-activated cell sorting (FACS) analysis of Mac-1 and 4/80 surface antigen expression. Once differentiated, the BMMs are suitable for numerous types of experimental manipulations, including morphological, gene expression, and physiological studies. For example, phagocytic cells such as macrophages have a unique ability to ingest microbes. We describe a test for the phagocytic efficiency of BMMs by exposing them to fluorescently labeled yeast zymosan bioparticles. Also, a method to deliver DNA or small interfering RNAs (siRNAs) into these hard-to-transfect cells is described. Finally, the proliferation of the BMMs is assayed using carboxyfluorescein succinimidyl ester (CFSE), a fluorescein derivative that partitions equally between daughter cells after cell division.

\section{MATERIALS}

CAUTIONS AND RECIPES: Please see Appendices for appropriate handling of materials marked with $\langle$ ! $\rangle$, and recipes for reagents marked with $<\mathbf{R}>$.

\section{Reagents}

Antibody, anti-mouse 4/80 antigen, allophycocyanin (APC)-conjugated (eBioscience) Antibody, anti-mouse CD16/32 (Fc block) (eBioscience) Antibody, anti-mouse Mac-1, fluorescein isothiocyanate (FITC)-conjugated (eBioscience) Cell line, murine, L929 (ECACC)

Celltrace CFSE Cell Proliferation Kit (Molecular Probes) $<$ !>DAPI (4',6-diamidino-2-phenylindole) (Molecular Probes)

$<$ !>Dimethyl sulfoxide containing $5 \mathrm{mM}$ carboxyfluorescein succinimidyl ester (CFSE stock) CFSE is a nonfluorescent cell-permeant. In the cytosol, CFSE is cleaved by esterases to an impermeant fluorescent molecule that can be used to track cell proliferation. Store in the dark.

Ethanol, 70\% 
Fetal bovine serum (FBS; Invitrogen)

$<$ !>FITC-labeled phalloidin (Fluka) (optional; see Step 24)

$<$ R $>$ Glycerol mounting medium

HEPES (Invitrogen)

$<$ R $>$ L929 medium

$<$ R $>$ Lymphocyte medium

$<$ R $>$ Lymphocyte medium containing 10\% L929-conditioned medium (see Step 3) (BMM medium)

Mice, 8-10 wk old

Mouse Macrophage Nucleofector Kit (Amaxa)

$<$ R $>$ Paraformaldehyde in PBS (4\% PFA)

$<\mathbf{R}>$ Phosphate-buffered saline (PBS), sterile (ice-cold for Step 20; prewarmed to $37^{\circ} \mathrm{C}$ for Step 48)

Plasmid or siRNA of interest

RPMI-1640 (Invitrogen)

$<$ ! $>$ Triton X-100 (Sigma)

$<$ !>Trizol (Invitrogen)

$<$ !>Trypsin, $1 X$ (Invitrogen)

Zymosan A BioParticles, Alexa Fluor 594-conjugated (Molecular Probes)

Zymosan A BioParticles opsonizing reagent (Molecular Probes) (optional; see Step 16)

\section{Equipment}

Cell strainer, nylon, 70- $\mu \mathrm{m}$ (BD Biosciences)

Centrifuge, benchtop

Coverslips

Cytocentrifuge

Dishes, tissue culture, 10- or 15-cm (TPP)

Filter, 0.45- $\mu \mathrm{m}$ (Millipore)

Flask, tissue culture, $75-\mathrm{cm}^{2}$ (TPP)

$<$ ! $>$ Flow cytometer, equipped with a 488-nm argon laser (e.g., FACSCalibur; BD Biosciences)

Forceps

Hemacytometer

Hood, laminar flow

Incubator, humidified, preset to $37^{\circ} \mathrm{C}$, pre-equilibrated with $5 \% \mathrm{CO}_{2}$

Microcentrifuge

Microscope, fluorescence

Mortar and pestle (optional; see Step 8)

Nail polish, clear (optional; see Step 27)

Needles, 25-gauge (optional; see Step 8)

Nucleofector II (AAD-1001; Amaxa)

Pipettes

Plates, cell culture, 12- or 24-well

Policeman, rubber or a flattened $1000-\mu \mathrm{L}$ pipette tip

Scissors, surgical

Slides, microscope

Syringes, 5-mL (optional; see Step 8)

Tubes, 15- and 50-mL

Tubes, microcentrifuge, $1.5-\mathrm{mL}$

Vortexer

\section{METHOD}

\section{Preparation of L929-Conditioned Medium}

1. Plate $4.7 \times 10^{5} \mathrm{~L} 929$ cells in a $75-\mathrm{cm}^{2}$ flask containing $55 \mathrm{~mL}$ of $\mathrm{L} 929$ medium.

2. Grow cells in a humidified incubator with $5 \% \mathrm{CO}_{2}$ at $37^{\circ} \mathrm{C}$ for $7 \mathrm{~d}$. 
3. Collect the supernatant. Filter through a $0.45-\mu \mathrm{m}$ filter. Store $50-\mathrm{mL}$ aliquots frozen at $-20^{\circ} \mathrm{C}$ (L929-conditioned medium).

\section{Bone Marrow Isolation and BMM Differentiation (Fig. 1)}

Sterile techniques are required during and after isolation of bone marrow cells. Rinse all utensils carefully with ethanol. Harvest bone marrow in a laminar flow hood.

4. Sacrifice mice by cervical dislocation.

5. Sterilize the abdomen and hind legs with $70 \%$ ethanol.

6. Make an incision in the midline of the abdomen. Clip outward to expose the hind legs.

7. Use scissors to remove all muscle tissue from the bones. Cut the bones at both ends to free them.

8. Crush the bones in a mortar with $5 \mathrm{~mL}$ of lymphocyte medium supplemented with $20 \mathrm{mM}$ HEPES. Alternatively, separate the femur and tibia by cutting at the knee joint. Flush the bones with lymphocyte medium using a 5-mL syringe and a 25-gauge needle.

9. Pipet the bone marrow cells up and down to bring the cells into single-cell suspension.

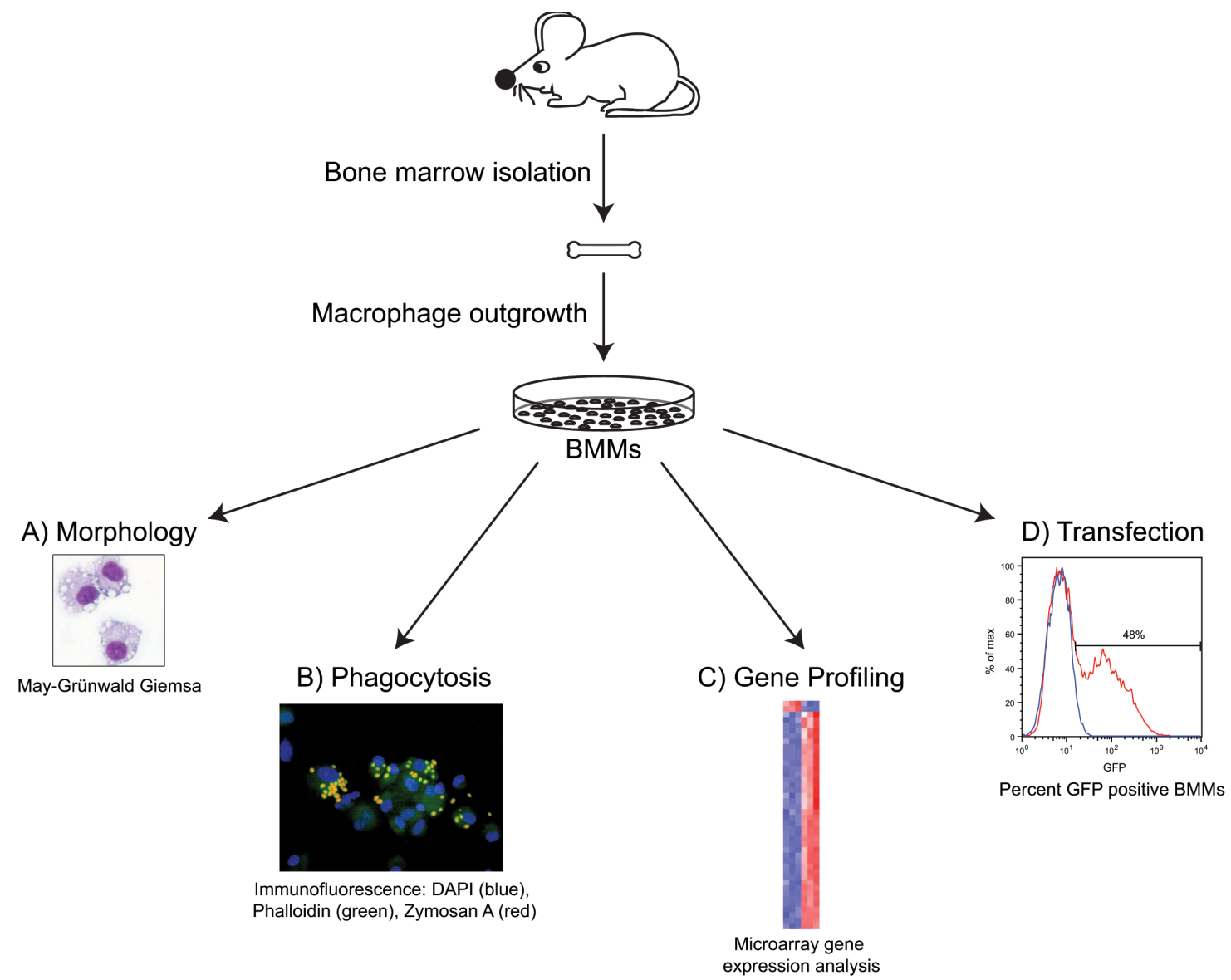

FIGURE 1. Flow chart of isolation and examples of applications for BMMs. Cells are isolated from bone marrow and cultured in vitro. BMMs are suitable for numerous applications including, but not limited to, the examples shown here. (A) Morphological examination of cytospins using histological stains (e.g., May-Grünwald-Giemsa staining to visualize nuclei and granules). (B) Assays for phagocytic capacity. Fluorescence microscopy is used to visualize DAPI-stained nuclei (blue), phalloidin-FITC-labeled cytoskeletons (green), and phagocytosed Alexa Fluor 594-conjugated zymosan A bioparticles (red). The zymosan A bioparticles appear yellow as they colocalize with the green phalloidin marker. (C) Gene expression analyses. Because of their homogeneity, BMMs are an excellent primary cell source. (D) Transfection studies. Transfection of BMMs using an Amaxa Nucleofector system results in 40\%-50\% transfection efficiency. BMMs were transfected with 1 $\mu \mathrm{g}$ of green fluorescent protein (GFP)-expressing plasmid and were assayed $24 \mathrm{~h}$ later for GFP expression (red) compared to mock transfected controls (blue). (For color figure, see doi: 10.1101/pdb.prot5080 online at www.cshprotocols.org.) 
10. Pass the cells through a cell strainer. Wash the strainer with another $5 \mathrm{~mL}$ of lymphocyte medium.

11. Count the bone marrow cells using a hemacytometer. Adjust the concentration to $2 \times 10^{6}$ cells $/ \mathrm{mL}$ in BMM medium.

12. Plate the cells as needed: e.g., $25 \mathrm{~mL}$ in a $15-\mathrm{cm}$ culture dish (for protein or nucleic acid extraction), $12 \mathrm{~mL}$ in a $10-\mathrm{cm}$ culture dish, $1 \mathrm{~mL}$ per well for 24-well or $2 \mathrm{~mL}$ per well for 12 -well plates (for phagocytosis assays).

13. Differentiate cells in a humidified incubator with $5 \% \mathrm{CO}_{2}$ at $37^{\circ} \mathrm{C}$. Wash cells twice with PBS every 2-3 d, and add fresh BMM medium.

Macrophage progenitors adhere to the cell dish and are not washed away. Macrophages are fully differentiated at day 6. Grow cells to be used for phagocytosis assays for $7 d$.

14. Process BMMs as required for assays for phagocytic activity (Steps 15-28), nucleic acid or protein extraction (Steps 29-30), or harvesting of intact cells (Steps 31-36) for subsequent experimentation.

\section{Phagocytosis Assay (Fig. 1B)}

All steps that include fluorescent dyes should be performed in the dark.

15. Incubate BMMs grown in BMM medium for $7 \mathrm{~d}$ in 12- or 24-well plates (from Step 13) for an additional $24 \mathrm{~h}$ in lymphocyte medium (i.e., BMM medium without L929-conditioned medium). This starves the cells for M-CSF.

16. Add $5 \mu \mathrm{L}$ of fluorescently labeled zymosan A bioparticles and $5 \mu \mathrm{L}$ of opsonizing reagent to a 1.5$\mathrm{mL}$ reaction tube containing $500 \mu \mathrm{L}$ PBS. Incubate at $37^{\circ} \mathrm{C}$ for $1 \mathrm{~h}$.

Opsonization is optional but increases phagocytosis.

17. Wash the bioparticles twice, $1 \mathrm{~mL}$ of PBS each wash, by centrifugation at $1250 \mathrm{~g}$ for $15 \mathrm{~min}$. Count the number of particles.

18. Wash the BMMs twice with RPMI-1640. Count an aliquot of the BMMs from a well. Calculate the number of bioparticles required to add for a multiplicity of infection (MOI) of 10 .

Alternatively, test a range of MOls, e.g., 5-25.

19. Briefly vortex the opsonized bioparticles. Centrifuge the particles onto the BMMs at $450 \mathrm{~g}$ for $2 \mathrm{~min}$. Incubate the samples in a humidified $37^{\circ} \mathrm{C}, 5 \% \mathrm{CO}_{2}$ incubator for $1 \mathrm{~h}$.

Remember to include a negative control.

20. Stop phagocytosis by adding ice-cold PBS. Wash the BMMs four times with cold PBS.

21. Scrape the cells with a rubber policeman (or a flattened $1000-\mu \mathrm{L}$ pipette tip). Centrifuge the cells onto microscope slides using a cytocentrifuge at $500 \mathrm{~g}$ for $5 \mathrm{~min}$.

Alternatively, cells can be fixed directly in wells. Perform all subsequent steps at room temperature in the dark.

22. Fix cells in freshly prepared 4\% PFA for 20 min. Wash twice with PBS.

23. Prepare PBS containing 1\% FBS and $0.5 \%$ Triton $X-100$. Permeabilize the cells with this solution for 15 min. Prepare PBS containing 1\% FBS (i.e., no Triton). Wash the cells three times with this solution.

24. (Optional) Prepare $1 \mu \mathrm{g} / \mathrm{mL}$ FITC-labeled phalloidin in PBS containing 10\% FBS. Stain the cells with this solution for $30 \mathrm{~min}$.

Phalloidin stains the actin cytoskeleton.

25. Prepare $1 \mu \mathrm{g} / \mathrm{mL}$ DAPI in PBS containing 1\% FBS. Remove the medium from the cells and add the DAPI. Incubate for $10 \mathrm{~min}$.

26. Wash the cells twice in PBS containing $1 \%$ FBS. Wash in $\mathrm{H}_{2} \mathrm{O}$. Air-dry briefly.

27. Mount coverslips with a few drops of glycerol mounting medium.

Optionally, seal the coverslips with clear nail polish.

28. Analyze the cells using a fluorescence microscope.

The phagocytic index is the average number of particles per 100 macrophages. 


\section{BMM Extraction}

29. Add $4 \mathrm{~mL}$ Trizol directly to a $15-\mathrm{cm}$ dish of BMMs. Resuspend the cells by pipetting. Transfer to tubes.

30. Extract RNA, DNA or protein according to the needs of the subsequent experiment.

\section{Harvesting BMMs}

The volumes used here are for cultures in a $15-\mathrm{cm}$ dish. Adjust accordingly for other dish sizes.

31. Wash cells with PBS. Add $4 \mathrm{~mL}$ of room-temperature trypsin. Swirl the dish briefly to mix. Incubate the samples for $5 \mathrm{~min}$ in the incubator at $37^{\circ} \mathrm{C}$.

32. Replace the trypsin with $4 \mathrm{~mL}$ of fresh trypsin. Incubate for $20-25 \mathrm{~min}$ at $37^{\circ} \mathrm{C}$ with occasional swirling.

Macrophages are very sticky.

See Troubleshooting.

33. Add $2 \mathrm{~mL}$ of additional trypsin. Resuspend the cells completely by pipetting.

34. Add $6 \mathrm{~mL}$ of lymphocyte medium. Resuspend the cells by pipetting. Transfer the cells to a $15-\mathrm{mL}$ tube.

35. Centrifuge at $200 \mathrm{~g}$ for $10 \mathrm{~min}$. Resuspend the pellet in fresh lymphocyte medium.

36. Process cells as required for FACS (Steps 37-40), transfection (Steps 41-47), or cell proliferation (Steps 48-51).

\section{Phenotypic Characterization of BMMs by FACS}

All steps are performed at $4^{\circ} \mathrm{C}$ in the dark.

37. Resuspend $5 \times 10^{5}$ BMMs in $200 \mu \mathrm{L}$ of lymphocyte medium supplemented with 20 mM HEPES. Add Fc block antibody (diluted 1:400). Incubate for $10 \mathrm{~min}$.

38. Add FITC-conjugated anti-Mac-1 and APC-conjugated anti-4/80 antibodies (both diluted 1:400) to the cells. Incubate for $30 \mathrm{~min}$ in the dark.

39. Centrifuge the cells at $300 \mathrm{~g}$ for $5 \mathrm{~min}$. Wash once by centrifugation with $200 \mu \mathrm{L}$ fresh lymphocyte medium. Resuspend in $300 \mu \mathrm{L}$ of fresh lymphocyte medium.

40. Analyze the cells by FACS.

Macrophages are double-positive for Mac-1 and 4/80.

\section{BMM Transfection (Fig. 1D)}

BMMs are transfected using Amaxa's Nucleofector device and a Mouse Macrophage Nucleofector kit.

41. Equilibrate the Mouse Macrophage Nucleofector Solution to room temperature.

42. Prepare lymphocyte medium containing $20 \%$ FBS. Fill the appropriate number of wells in 12 -well plates with $1.5 \mathrm{~mL}$ of this medium. Preincubate the plates in a humidified incubator with $5 \% \mathrm{CO}_{2}$ at $37^{\circ} \mathrm{C}$.

43. Count harvested BMMs (from Step 36). Centrifuge at $200 \mathrm{~g}$ for $10 \mathrm{~min}$. Resuspend the cells in Nucleofector Solution to a concentration of $1 \times 10^{6}$ cells $/ 100 \mu \mathrm{L}$ (minimum $100 \mu \mathrm{L}$ ).

44. Add 1-2 $\mu \mathrm{g}$ of plasmid DNA or siRNA to a $1.5-\mathrm{mL}$ tube. Add $100 \mu \mathrm{L}$ of the BMM/Nucleofector mix to the plasmid or siRNA. Mix gently. Transfer to a certified Amaxa cuvette. Make sure that the solution covers the bottom. Avoid air bubbles.

45. Process the sample immediately using the Nucleofector II device, program Y-001**.

46. Add $500 \mu \mathrm{L}$ of the plated medium (from Step 42) to the cuvette. Transfer the diluted cell suspension back into the prepared 12-well plate. 
47. Incubate the cells in a humidified incubator with $5 \% \mathrm{CO}_{2}$ at $37^{\circ} \mathrm{C}$ for $24-48 \mathrm{~h}$.

The cells can now be used for subsequent experiments.

See Troubleshooting.

\section{Cell Proliferation Assay}

48. Dilute the CFSE stock to $5 \mu \mathrm{M}$ with PBS prewarmed to $37^{\circ} \mathrm{C}$.

49. Remove the medium from the BMMs (from Step 36). Add the CFSE. Incubate the cells in a humidified incubator with $5 \% \mathrm{CO}_{2}$ at $37^{\circ} \mathrm{C}$ for $15 \mathrm{~min}$.

Remember to include a negative control.

50. Wash the cells. Replace with fresh BMM medium.

51. Track cell division by FACS analysis of CFSE on FL-1 using a FACSCalibur. Calculate the number of cell divisions using the Flowjo Proliferation function.

CFSE has substantial fluorescein emission into FL-2, which requires extensive compensation. See Troubleshooting.

\section{TROUBLESHOOTING}

Problem: BMMs are difficult to trypsinize.

[Step 32]

Solution: Flush the cells carefully with trypsin after incubation for 20-25 min. Use prewarmed trypsin.

Problem: BMM transfection fails.

[Step 47]

Solution: Using $<100 \mu \mathrm{L}$ Nucleofector solution will cause a failure in Amaxa Nucleofector transfection. Make sure the transfection solution covers the bottom of the cuvette, and avoid air bubbles.

Problem: CFSE emission is too bright for FACS analysis.

[Step 51]

Solution: Use a lower concentration of CFSE. Normally, CFSE emission is too bright the same day or even the day after. Wait two or more days before analyzing.

\section{DISCUSSION}

BMMs are an excellent model to study various mechanisms in a primary cell culture. Compared to many other primary cells, the BMMs are homogenous, have a proliferative capacity, are transfectable, and have a lifespan longer than a week. In fact, BMMs can be grown up to three weeks without noticeable cell death or altered morphology. BMMs can be used as a primary cell culture system to study gene function in vitro (e.g., ablating gene expression in transgenic mice). Altered proliferation, function, and gene expression can all be analyzed using BMMs (Weischenfeldt et al. 2008). Additionally, macrophages are specialized cells that carry out numerous tasks in the immune system such as phagocytosis, antigen presentation, cytokine production, and migration. The BMMs represent a tractable system to assay these functions in cell culture (Kanters et al. 2003; Doyle et al. 2004; Cho et al. 2007).

\section{REFERENCES}

Cho, Y.J., Cunnick, J.M., Yi, S.J., Kaartinen, V., Groffen, J., and Heisterkamp, N. 2007. Abr and Bcr, two homologous Rac GTPase-activating proteins, control multiple cellular functions of murine macrophages. Mol. Cell. Biol. 27: 899-911.

Doyle, S.E., O'Connell, R.M., Miranda, G.A., Vaidya, S.A., Chow, E.K., Liu, P.T., Suzuki, S., Suzuki, N., Modlin, R.L., Yeh, W.C., et al. 2004. Toll-like receptors induce a phagocytic gene program through p38. J. Exp. Med. 199: 81-90.

Kanters, E., Pasparakis, M., Gijbels, M.J., Vergouwe, M.N., Partouns-
Hendriks, I., Fijneman, R.J., Clausen, B.E., Förster, I., Kockx, M.M., Rajewsky, K., et al. 2003. Inhibition of NF-kappaB activation in macrophages increases atherosclerosis in LDL receptor-deficient mice. J. Clin. Invest. 112: 1176-1185.

Weischenfeldt, J., Damgaard, I., Bryder, D., Theilgaard-Mönch, K., Thoren, L.A., Nielsen, F.C., Jacobsen, S.E., Nerlov, C., and Porse, B.T. 2008. NMD is essential for hematopoietic stem and progenitor cells and for eliminating by-products of programmed DNA rearrangements. Genes \& Dev. 22: 1381-1396. 


\title{
Bone Marrow-Derived Macrophages (BMM): Isolation and Applications
}

\author{
Joachim Weischenfeldt and Bo Porse
}

Cold Spring Harb Protoc; doi: 10.1101/pdb.prot5080

\begin{tabular}{rc}
$\begin{array}{r}\text { Email Alerting } \\
\text { Service }\end{array}$ & Receive free email alerts when new articles cite this article - click here. \\
\hline Subject & Browse articles on similar topics from Cold Spring Harbor Protocols. \\
Categories & Cell Biology, general (1382 articles) \\
& Cell Culture (301 articles) \\
& DNA Delivery/Gene Transfer (344 articles) \\
& DNA Delivery/Gene Transfer, general (341 articles) \\
& Flow Cytometry (42 articles) \\
& Fluorescence (517 articles) \\
& Fluorescence, general (341 articles) \\
& Isolation (34 articles) \\
& Laboratory Organisms, general (923 articles) \\
& Live Cell Imaging (274 articles) \\
& Mouse (437 articles) \\
RNA Interference (RNAi)/siRNA (123 articles) & \\
\hline
\end{tabular}

